\title{
The influence of camera angle on comprehension and retention of pictorial events
}

\author{
ROBERT N. KRAFT \\ Grinnell College, Grinnell, lowa
}

\begin{abstract}
A subset of formal compositional principles was examined in the context of narrative pictorial events. Slide stories were constructed of six common events in which characters were depicted from three camera angles: low angle, eye-level, and high angle. After presentation, subjects evaluated the characters, recalled the stories, and engaged in a recognition task. Camera angle influenced subjects' evaluation and retention of the stories in accordance with aesthetic principles. Camera angle had significant, predictable effects on judgments of the physical and personal characteristics of the characters, on recall of these characteristics, and on recall of the gist of the stories themselves. Recognition memory for camera angle was significantly less accurate than recognition memory for the characters. Subjects used the available visual information to construct coherent story representations, and, although camera angle strongly influenced the construction of these representations, specific camera angle information became less accessible.
\end{abstract}

When creating a pictorial event, the photographer selects a particular frame of reference for the viewer: the lighting, the camera angle, the perspective, the lines and forms, the framing, the balance, and the overall compositional arrangement (e.g., Arnheim, 1974; Giannetti, 1982; Monaco, 1981; Nelson, 1977; Sontag, 1977; Taylor, 1964). In short, the recorder of the pictorial event controls the manner in which the information is presented. Moreover, every choice of angle, lighting, or perspective may affect the viewer's understanding and subsequent memory for the pictorial event (Arnheim, 1974; Hevner, 1935; Kraft, Patterson, \& Mitchell, 1986; Poore, 1903; Shoemaker, 1964; Tannenbaum \& Fosdick, 1960). It is important, then, in the investigation of pictorial events to consider the compositional form of the display as well as the pictorial content.

The lively and growing area of research on picture memory has focused mainly on issues of content rather than form. The distinction here between pictorial form and content is analogous to that made by Craik and Lockhart (1972) regarding linguistic materials: formal characteristics are concerned with the structure of the information; content involves general semantic characteristics (Huston et al., 1981). Specifically, recent research on memory for complex pictures has focused on three issues: what types of information are normally encoded, how this information is represented in memory, and to what degree picture memory can be affected by different orienting tasks. This research on the content analysis of our memory for complex pictures has engendered investigations for more narrative forms of pictorial communication, such as representation of picture stories (Baggett, 1975;

\footnotetext{
This paper was strengthened and clarified by the thoughtful suggestions of James J. Jenkins, Ulric Neisser, and Alice F. Healy. Thanks are due to the students of Grinnell College who participated in this study. Send reprint requests to Robert N. Kraft, Psychology Department, Grinnell College, Grinnell, IA 50112.
}

Jenkins, Wald, \& Pittenger, 1978; Kraft \& Jenkins, 1977; Leibrich \& White, 1983; Pittenger \& Jenkins, 1979) and narrative films (Baggett, 1979; Carroll \& Bever, 1976; Wald, 1980). In the wave of experimentation on memory for pictorial material, however, there has been only a ripple of research on the formal compositional properties of the pictures.

There is a rich and detailed collection of writings in the aesthetic film literature concerning the effects of formal photographic and cinematic techniques on the meaning of the filmed message. Film directors, cinematographers, photographers, screen writers, and philosophers have described in varying detail the psychological effects of various manipulations of pictorial composition (e.g., Andrew, 1976; Arnheim, 1974; Ball, 1965; Chandler \& Barnhart, 1938; Coynik, 1974; Eisenstein, 1949; Giannetti, 1982; Kracauer, 1960; Mascelli, 1965; Metz, 1974; Monaco, 1981; Pudovkin, 1958; Sontag, 1977).

Several contemporary research programs have been investigating the general issue of formal or expressive cinematic techniques. Hochberg and Brooks (Hochberg, 1978; Hochberg \& Brooks, 1978a, 1978b) are comprehensively examining the nature of perceiving edited cinematic sequences. Anderson and colleagues (Alwit, Anderson, Lorch, \& Levin, 1980; Anderson \& Smith, 1984) and Huston and Wright (1983; Huston et al., 1981) are identifying formal features of television programs and investigating the attentional effects of these features on the developing child. Salomon $(1974,1979)$ is examining the effects of visual conventions of television on the information processing of young viewers. One potentially productive research track, then, is to assess the psychological validity of compositional principles in the context of contemporary research on memory for complex pictorial events.

Shoemaker (1964) conducted a set of experiments to assess the psychological reality of a subset of composi- 
tional principles concerning camera angle. More specifically, Shoemaker examined the effects of three levels of vertical camera angle-high, eye-level, and low-on viewers' judgments of connotative meaning for photographs of three male models. Subjects judged the photographs along rating scales of the semantic differential (Osgood, Suci, \& Tannenbaum, 1957), five apiece from the evaluation factor, the activity factor, and the potency factor. A significant effect of vertical camera angle was obtained on all three factors of connotative meaning. The low-angle photographs were judged evaluatively better, more active, and more potent than the high-angle photographs, which is congruent with previously untested notions in the aesthetic film literature (Coynik, 1974; Giannetti, 1982).

Shoemaker's (1964) study represents a good point of departure for future research; camera angle can predictably affect the connotative meaning of photographic material. In light of more recent research on pictorial events, however, two criticisms of the earlier research arise. First, comprehension and memory for pictorial events should be further elaborated with a variety of dependent variables, and not simply those that assess connotative meaning. The folklore of filmmaking suggests that effective visual manipulation involves manipulation of one level of comprehension (e.g., connotative meaning) without awareness at another level (e.g., recognition) (Mascelli, 1965; Tannenbaum \& Fosdick, 1960). Perhaps manipulations of compositional variables affect connotative meaning and recall of a given event, but not recognition memory. Research on compositional variables should make use of several measures of comprehension and memory: (1) measures of connotative meaning, (2) free recall, (3) cued recall, and (4) recognition, in order to tap the various levels of representation and to examine the implications of interactions among the different levels.

Second, this research should examine compositional principles in the context of narrative events. That is, past research has shown that compositional features can affect viewers' evaluations of snapshots (Shoemaker, 1964; Tannenbaum \& Fosdick, 1960); however, a more compelling issue-one that has more application to real-world phenomena - concerns the effect of compositional features on viewers' comprehension and memory for pictorial sequences that are presented as meaningful stories.

The present experiments extended the research on pictorial composition in two ways: (1) by examining several levels of comprehension and memory and (2) by presenting the pictorial materials in the context of visual narratives. These experiments examined one subset of compositional principles, that concerning camera angle. Camera angle was selected because of prior empirical documentation of its effects with individual photographs (Shoemaker, 1964) and, more importantly, because the effects associated with each angle may not be the result of learned aesthetic conventions, but rather may be derived from the natural visual relationship between the viewers and the characters being depicted. That is, a lowangle shot forces the viewers to look up at the actors, placing the actors in a position of visual authority and dominance. An eye-level shot places the viewer face-toface with the actors, producing visual parity. A high-angle view forces the viewer to look down on the actors, providing a higher vantage point and placing the viewers in a position of visual dominance. Giannetti (1982) stated that camera angles in a visual narrative are comparable to adjectives in a linguistic narrative. Angles modify the content, shaping the connotative meaning of the depicted characters and events. Low angles connote strength, action, and superiority; eye-level shots connote parity; high angles connote weakness, passivity, and insignificance.

The present research endeavored to assess the psychological reality of the compositional principles governing camera angle and to explore the mechanisms by which these principles operate, splicing together aesthetic observation and recent experimental work on memory for complex pictorial events. Through a series of measures, Experiment 1 assessed the influence of camera angle on the evaluation and recall of visual narratives. This experiment represented the major empirical manipulation, integrating evaluative judgments with free recall and recognition of the presented materials. Experiments 2 and 3 represented secondary manipulations to control for possible order effects in Experiment 1.

\section{EXPERIMENT 1}

The general goal of Experiment 1 was to assess the psychological reality of the photographic principles concerned with vertical camera angle. More specifically, this experiment examined the extent to which manipulations of vertical camera angle can affect viewers' evaluations of characters in a story, viewers' recall of the characters and of the story as a whole, and viewers' recognition memory.

The general hypotheses tested in Experiment 1 were as follows: (1) changes in vertical camera angle can alter the evaluation of characters in a story, and in the manner specified by the aesthetic literature: low angles connote strength, action, and superiority; eye-level shots connote parity; high angles connote weakness, passivity, and insignificance; (2) changes in vertical camera angle can affect subjects' recall of the characters in a story and the gist of the story itself; and (3) recognition memory for vertical camera angle is relatively inaccurate; that is, vertical camera angle may be transparent, or at least translucent, when measured with a recognition test.

\section{Method}

Subjects. Forty-two students enrolled in the introductory psychology course at Grinnell College served as subjects. Subjects were run in three groups of 14 . In addition, six staff members at Grinnell College were selected to be judges for the analysis of free-recall protocols.

Materials. Six four-slide stories were constructed from slides taken of six staged activities. Five of the six stories involved two characters performing a relatively common activity, and one story 
involved a person and a central object. The six stories were as follows: (1) "Boxes": a woman walks down the sidewalk and encounters a pile of boxes; (2) "The Encounter": two dolls greet each other; (3) "The Smoker": a woman tells a man to put out his cigarette; (4) "Hitchhiker": a driver picks up a hitchhiker; (5) "Basketball": two men play a one-on-one game of basketball; and (6) "The Dented Car": a man and a woman are involved in a mild car accident.

The first two slides in each story set up the activity, the third slide showed the first character, and the fourth slide showed the second character. (In the case of "Boxes," the first character was the pile of boxes and the second character was the woman walking.) While constructing the slide stories, the third and fourth slides of each story were shot at three different vertical camera angles: (1) high angle, (2) eye-level, and (3) low angle. The three different shots of each character were taken successively, and each actor was explicitly instructed to maintain a constant, neutral expression throughout. Each trio of shots (low, eye-level, and high) was taken several times to ensure consistency of expression and detail. Each story was then arranged into three different versions, depending on the angles of the third and fourth slides. That is, a particular version was defined according to the vertical camera angle of the first and second characters in each story. Version 1 presented a lowangle shot of the first character and a high-angle shot of the second character (Character 1 dominant). Version 2 presented both characters in eye-level shots (neutral). Version 3 presented a high-angle shot of the first character and a low-angle shot of the second (Character 2 dominant). Figure 1 presents black-and-white photographs of the three pairs of character shots for Versions 1,2, and 3 of "Basketball." There were three such versions for each of the six stories. In addition, one practice story was constructed: "Leaving Work": a woman leaves her office for the day. The same actors appeared
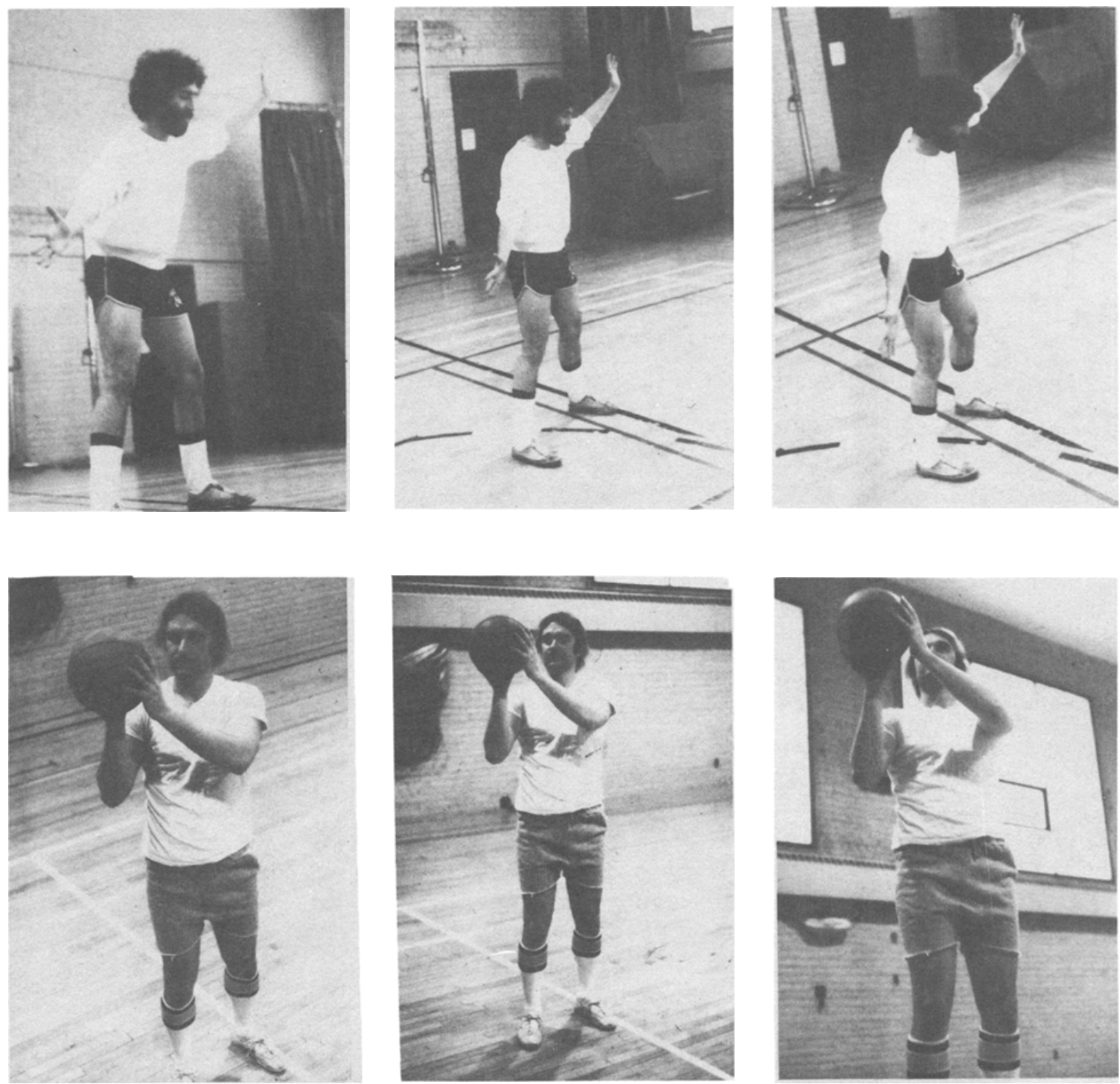

Figure 1. Black and white photographs of the three pairs of character shots for the three versions of "Basketball." Character shots for Version 1 are on the left (low-high), character shots for Version 2 are in the center (eye-eye), and character shots for Version 3 are on the right (high-low). The photographs are used with permissions of Frank Hassebrock and Arnie Josefowitz. 
in all three versions of a given story, and no actor appeared in more than one story. Each of the characters was depicted in a full-body medium shot; the camera was placed approximately $7 \mathrm{ft}(2.1 \mathrm{~m})$ away from each of the adult actors, $1.5 \mathrm{ft}(.5 \mathrm{~m})$ away from the dolls in "The Encounter," and $5 \mathrm{ft}(1.5 \mathrm{~m})$ away from the boxes in "Boxes." The vertical angle for low- and high-angle shots was approximately $40^{\circ}$ off eye level. All the slides were standard color slides.

The seven stories (one practice story and six target stories) were arranged in a fixed order. "Leaving Work" was presented first, and the target stories were presented in the following order: (1) "Boxes," (2) "The Encounter," (3) "The Smoker," (4) "Hitchhiker," (5) "Basketball," and (6) "The Dented Car."

Each slide story was preceded by a slide showing its title. Each slide was shown for 5 sec by a Kodak Carousel slide projector that was located approximately $10 \mathrm{ft}$ from the projection screen.

Procedure. Subjects performed three separate tasks with the stories. (1) After each story was presented, subjects rated the characters in the story along a variety of 7 -point rating scales. For a given story, all subjects were allowed to complete the rating task before the next story was presented. The average time for each set of ratings was approximately $80 \mathrm{sec}$. (2) After all seven stories were presented, subjects were given approximately $20 \mathrm{~min}$ to engage in a recall task concerning the six target stories. The stories were tested in the order in which they were originally presented. (3) After the recall task, subjects performed a recognition test.

The rating scales were constructed in the following manner. Six 7-point scales were adapted from the semantic differential (Osgood et al., 1957) and were used for all six stories. These scales were presented in the following order: (1) short/tall, (2) weak/strong, (3) afraid/unafraid, (4) timid/bold, (5) passive/aggressive, and (6) good/bad. The scales were selected because they tapped the three major factors of the semantic differential (Osgood et al., 1957), and because they were particularly sensitive to the potential connotative meanings of the six target stories. In addition to these six scales, the characters were evaluated with respect to two extra scales appropriate to each story. For each story, these two extra scales were presented after the first six.

The additional rating scales, specific to each of the six stories, were analyzed separately by story. For each additional scale, difference scores were computed for the ratings of the two characters in each of the three versions of a given story. That is, for each additional scale, the analysis involved a comparison of the three difference scores from Versions 1, 2, and 3: (1) first character (low) minus second character (high), (2) first character (eye-level) minus second character (eye-level), and (3) first character (high) minus second character (low). The difference scores were used to reveal the extent to which the relative ratings of the two characters in each story changed as a function of camera angle. Thus, for each scale of a given story there was a one-way between-subjects analysis comparing the difference scores across the three versions. It should be noted that this analysis was carried out for five of the six target stories. The remaining story, "Boxes," was analyzed differently because the two characters in this story (the boxes and the woman walking) were themselves rated along different scales; here, each character was examined separately.

The additional scales chosen for each target story were selected in order to tap more precisely the potential changes in connotative meaning unique to each story line. The following additional scales were selected: (1) "Boxes"-boxes: (a) hindering/not hindering and (b) small/large; woman: (a) frustrated/not frustrated and (b) upset/calm; (2) "The Encounter": (a) promiscuous/cautious and (b) liberal/conservative; (3) "The Smoker": (a) submissive/dominant and (b) relenting/steadfast; (4) "Hitchhiker": (a) nice/mean and (b) safe/dangerous; (5) "Basketball": (a) slow/quick and (b) unskillful/skillful; and (6) "The Dented Car": (a) guilty/innocent and (b) angry/ashamed.
There were three general recall questions for each target story: (1) describe (first character); (2) describe (second character); (3) describe what happened in (story name). Subjects were instructed to provide a one- or two-sentence answer to each question, giving their general impressions.

The recognition test was composed of three kinds of slides: (1) old-duplicates of the original slides, (2) new angle-slides of the original characters shot at a different camera angle, and (3) new content-unfamiliar characters. The entire test involved a total of 32 slides: (1) 16 new-content slides, (2) 8 old slides from the original stories, and (3) 8 new-angle slides. The set of old slides and newangle slides comprised 12 character slides plus 4 of the set-up slides in the target stories. The 4 set-up slides always represented the same angle in the stories as in the recognition sequence. The character slides were either the same or different with respect to camera angle. There were three "same" relationships between presentation and recognition: low-low (LL), eye-eye (EE), and high-high (HH), and there were six "different" relationships: low-high (LH), loweye (LE), eye-high (EH), eye-low (EL), high-low (HL), and higheye (HE). Three separate groups of subjects were run to balance the recognition design. Each group of subjects viewed 4 "same" character slides for a total of 12 across the three groups, 4 of each kind (LL, EE, and HH). Each group of subjects viewed 8 "different" character slides for a total of 24 across the three groups, 4 of each kind (LH, LE, EH, EL, HL, and HE). With this design, all relationships between the original angle of the character shot and the test angle were represented equally. Character slides from the original stories were presented in random order during the recognition task, with the stipulation that one character shot from each story be in the first half of the recognition sequence and the other character shot be in the second half. Each character shot appeared once in the presentation sequence and once in the recognition sequence. New content slides depicted characters and situations that were not shown in the original events.

For the test, subjects were instructed to circle "No" on their recognition sheets when a new character was presented (new-content slides). Subjects were instructed to circle "Yes" on their recognition sheets when familiar content was presented, regardless of the angle of the shot (old slides and new-angle slides). After the subjects responded "Yes," they were then required to indicate whether the slide was shot from the "same" angle or a "different" angle. Thus, there were 16 slides to which the subjects should respond "No" and 16 slides to which the subjects should respond "Yes." Of the 16 "Yes" slides, there were 8 slides to which the subjects should respond "Same" and 8 slides to which the subjects should respond "Different." The recognition test was constructed in this manner so that the stimulus materials themselves would not bias the subjects' responses.

Design. Each subject viewed two Version 1 stories (low/high), two Version 2 stories (eye/eye), and two Version 3 stories (high/low) for a total of six different stories. Order of presentation of the different versions was completely counterbalanced across subjects. For the six general rating scales, two separate analyses were performed. The variable of primary interest was vertical camera angle, which was divided into three levels: low angle, eye-level, and high angle. The first analysis separately examined the first and second characters in the three versions of the stories, resulting in a 2 (character) $\times 3$ (version) within-subjects design. The second analysis represented a one-way within-subjects design for the three levels of camera angle. The additional rating scales, specific to each of the six stories, were analyzed separately by story.

Recall data were analyzed in three ways. First, a general comparison of adjective use was conducted across the three different versions of the stories. Second, a specific analysis of key adjectives was conducted for each story. Third, independent judges evaluated the recall protocols from each story with regard to plot struc- 
ture. Analysis of recognition data involved a within-subjects comparison of subjects' ability to discriminate old- and new-content slides versus old- and new-angle slides.

\section{Results and Discussion}

Rating data. Figure 2 summarizes the results from the six common rating scales for the first and second characters in each of the three versions of the six stories. An analysis of variance (ANOVA) was conducted on the results from the rating scales in order to demonstrate the importance of vertical camera angle in defining the roles of the two characters in each story. The 2 (first character vs. second character) $\times 3$ (Version 1 vs. Version 2 vs. Version 3) within-subjects ANOVA yielded only two significant main effects for character. Apparently, subjects judged the characters introduced first to be bolder $[F(1,41)=4.12, M S \mathrm{e}=1.02, p<.05]$ and better $[F(1,41)=21.24, M S \mathrm{e}=.53, p<.001]$ than the second characters. There were no significant main effects for version. However, five of the six scales yielded significant interaction effects at the .001 level. The results of the interactions are as follows: short/tall $[F(2,82)=$ $18.58, M S e=.964]$; weak/strong $[F(2,82)=15.05, M S e$ $=$.993]; afraid/unafraid $[F(2,82)=10.49, M S \mathrm{e}=1.00]$; timid/bold $[F(2,82)=14.15, M S e=1.07]$; passive/aggressive $[F(2,82)=15.21, M S e=1.08]$; $\operatorname{good} / \mathrm{bad}[F(2,82)=1.57, M S \mathrm{e}=1.00]$. (The $S D$ s for the 36 means shown in Figure 2 ranged from .74 to 1.20.)

These results show that the relationship between the ratings of the two characters in each story actually reversed itself from Version 1 to Version 3 for the following five scales: (1) short/tall, (2) weak/strong, (3) afraid/unafraid, (4) timid/bold, and (5) passive/aggressive. In general, camera angle strongly defined the relative roles of the two characters in each story.

Figure 3 summarizes the results from the six common rating scales for each of the three camera angles. That is, a simple one-way analysis was conducted comparing the results of high-angle shots versus eye-level shots versus low-angle shots. There was a significant main effect of angle in the predicted direction with five of the six scales at the .001 level: (1) short/tall $[F(2,82)=$ 29.32, $M S e=.326]$; (2) weak/strong $[F(2,82)=24.46$, $M S e=.336] ;(3)$ afraid/unafraid $[F(2,82)=18.15, M S e$ $=.271] ;$ (4) timid/bold $[F(2,82)=17.58, M S e=.437]$; and (5) passive/aggressive $[F(2,82)=21.80, M S e=$ .4511 . The effect of angle on the good/bad scale was not significant $[F(2,82)=3.08, M S \mathrm{e}=.235, p>.05]$. (The

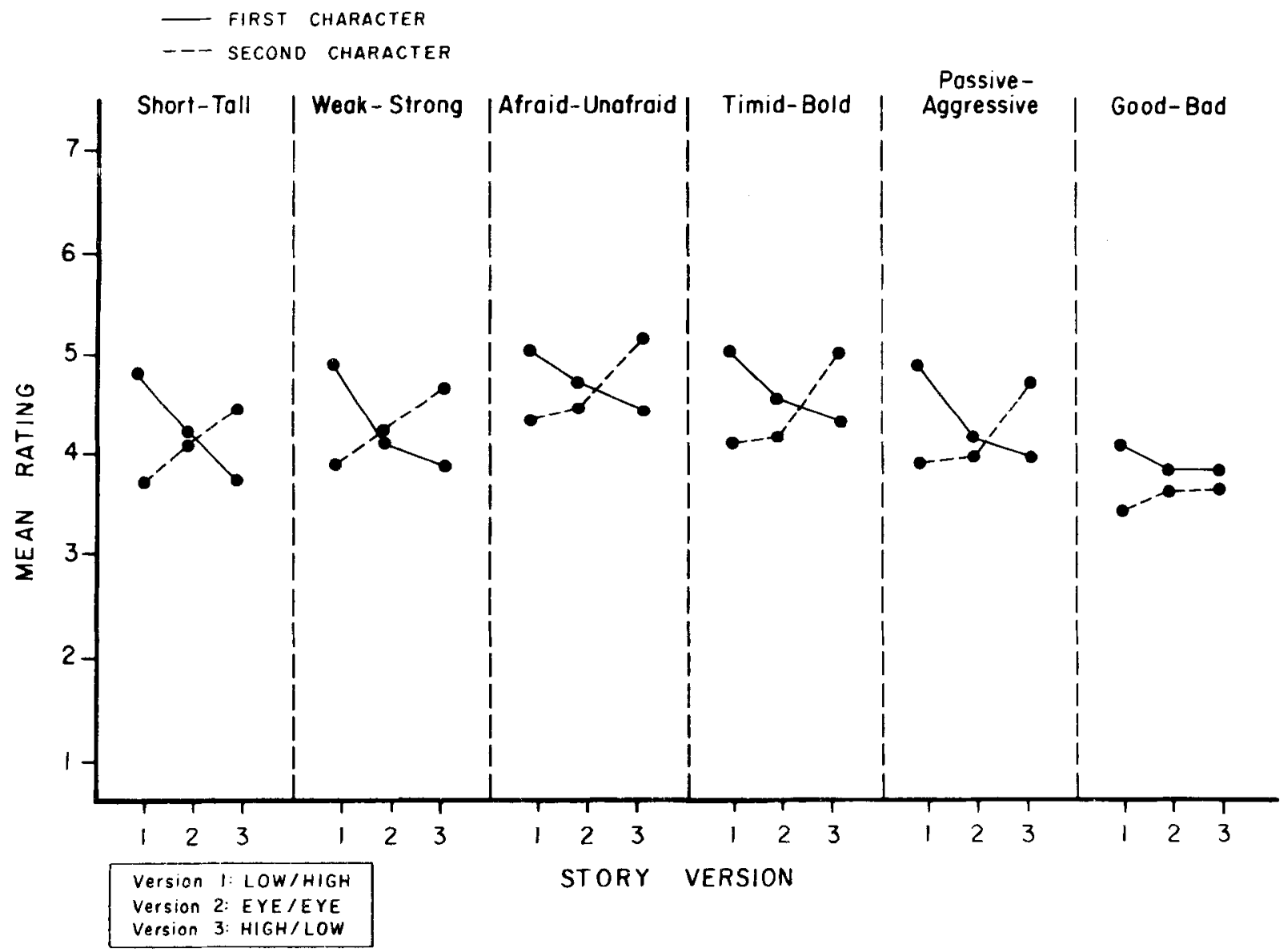

Figure 2. Ratings of the first and second characters for the three versions of the stories in Experiment 1. 


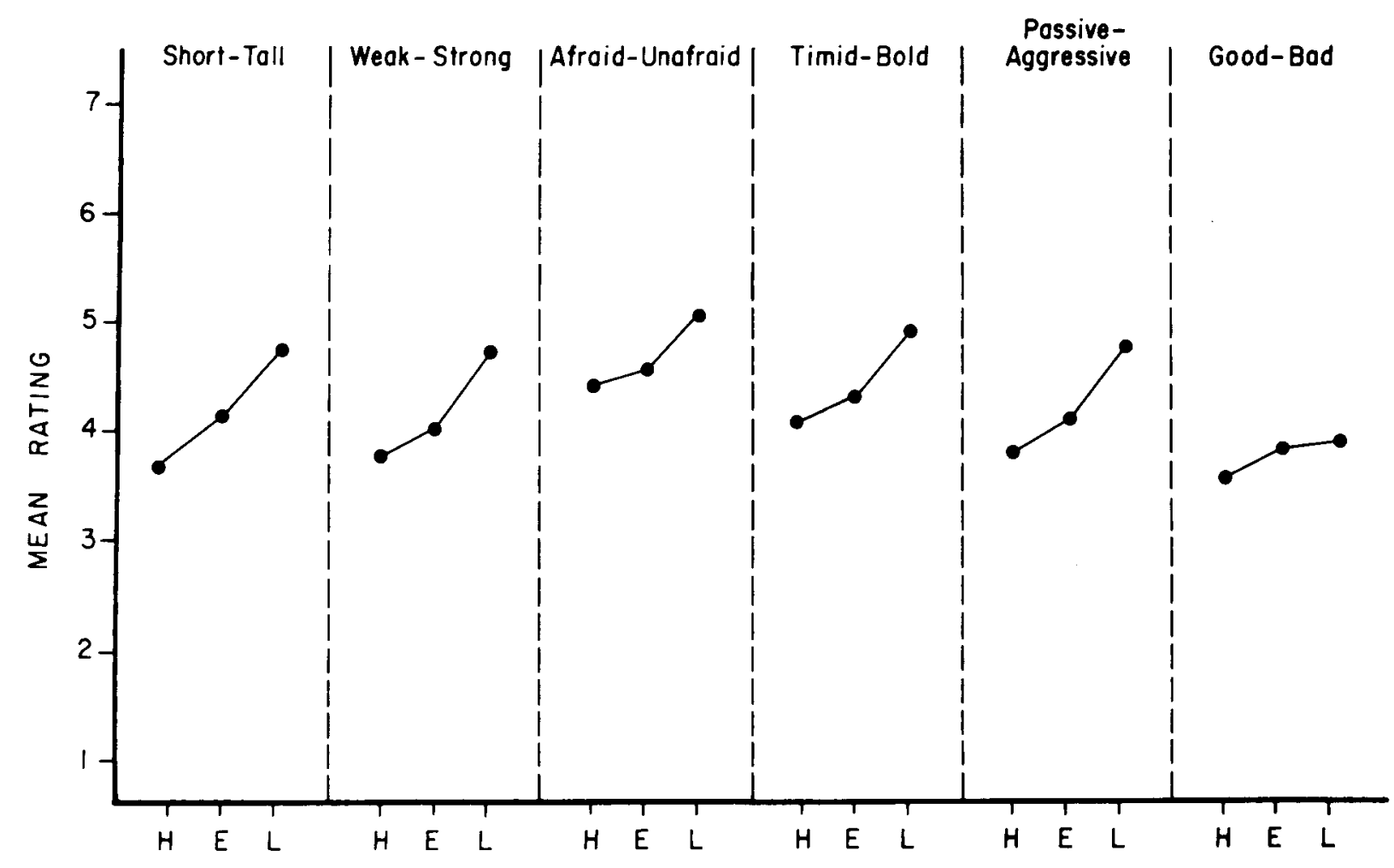

CAMERA ANGLE

Figure 3. Connotative meaning as a function of three vertical camera angles: (1) high (H), (2) eye-level (E), and (3) low (L) in Experiment 1.

$S D$ s for the 18 means shown in Figure 3 ranged from .48 to .73.) In general, as one changes from a high-angle shot to an eye-level shot to a low-angle shot, the characters in these shots appear taller, stronger, more unafraid, bolder, and more aggressive.

The additional rating scales, specific to each story, were analyzed separately by story. For "Boxes," camera angle significantly affected how large the boxes appeared $[F(2,39)=8.70, M S e=1.30, p<.001]$. The mean ratings on the small/large scale for low-angle, eye-level, and high-angle shots were $4.50,3.97$, and 2.71 , respectively. The corresponding standard deviations were $1.02,1.12$, and 1.27. Table 1 shows the results and the analysis of the two additional rating scales for each of the remaining five stories. For each scale, the adjective anchoring the low end of the scale is listed first and the adjective anchoring the high end is listed underneath. For example, at the bottom of Table 1 in "The Dented Car," the adjective "angry" anchored the low end and the adjective "ashamed" anchored the high end of the angry/ashamed scale. Each difference score was computed by subtracting the mean rating for Character 2 from the mean rating for Character 1. A positive difference score means that Character 1 received a higher mean rating than Character 2. A negative difference score means that Character 1 received a lower mean rating than Character 2. For example, in Version 1 of "The Dented Car,"
Character 1 (low angle) was judged to be less ashamed than Character 2 (high angle) by 1.93 units on the rating scale. In Version 2, Character 1 (eye-level) was still judged to be less ashamed than Character 2 (eye-level), but by only .71 units. Finally, in Version 3, the relationship between the two characters was reversed; Character 1 (high angle) was judged to be more ashamed than Character 2 (low angle) by 2.36 units.

Three of the five stories demonstrated a significant effect of camera angle on both scales. Vertical camera angle made a significant difference in how dominant and how steadfast the man and the woman appeared in "The Smoker," how mean and how dangerous the hitchhiker and the driver appeared in "Hitchhiker," and how guilty and how ashamed the characters appeared in "The Dented Car." Thus, camera angle influenced not only the general connotative meanings associated with the characters, but also the connotative meanings specific to a given story line.

Recall data. Giannetti (1982) stated that camera angles in a visual narrative are comparable to adjectives in a linguistic narrative. Moreover, the more extreme the angle (high or low), the stronger the adjectival meaning. Extreme camera angles may indeed function as visual adjectives. If subjects were required to recall two written passages, and the recall protocols from Passage A contained more adjectives than those from Passage B, it 
Table 1

Difference Scores for the Two Additional Rating Scales for Each Target Story in Experiment 1

\begin{tabular}{|c|c|c|c|c|c|c|}
\hline Target Story & Scale & $\begin{array}{c}\text { Version 1 } \\
\left(\text { Low }_{1}-\text { High }_{2}\right)\end{array}$ & $\begin{array}{c}\text { Version } 2 \\
\left(\text { Eye }_{1}-\text { Eye }_{2}\right)\end{array}$ & $\begin{array}{c}\text { Version } 3 \\
\left(\text { High }_{1}-\text { Low }_{2}\right)\end{array}$ & $F$ Value* & $M S \mathrm{e}$ \\
\hline \multirow[t]{2}{*}{ The Encounter } & $\begin{array}{l}\text { Promiscuous/ } \\
\text { Cautious }\end{array}$ & -1.21 & -1.21 & -.79 & .17 & 4.95 \\
\hline & $\begin{array}{l}\text { Liberal/ } \\
\text { Conservative }\end{array}$ & -.43 & -.86 & -1.57 & 1.59 & 2.94 \\
\hline \multirow[t]{2}{*}{ The Smoker } & $\begin{array}{r}\text { Submissive/ } \\
\text { Dominant }\end{array}$ & +.64 & -1.86 & -1.50 & $13.06 \dagger$ & 1.96 \\
\hline & $\begin{array}{l}\text { Relenting/ } \\
\text { Steadfast }\end{array}$ & +.50 & -1.36 & -1.79 & $7.26 \ddagger$ & 2.85 \\
\hline \multirow[t]{3}{*}{ Hitchhiker } & $\begin{array}{l}\text { Nice/ } \\
\text { Mean }\end{array}$ & +1.14 & -.93 & -.93 & $6.32 \ddagger$ & 3.17 \\
\hline & Safe/ & & & & & \\
\hline & Dangerous & +1.86 & -.50 & -.36 & $5.12 \S$ & 4.78 \\
\hline \multirow[t]{2}{*}{ Basketball } & $\begin{array}{l}\text { Slow/ } \\
\text { Quick }\end{array}$ & +.64 & +.43 & -.79 & 1.92 & 4.33 \\
\hline & $\begin{array}{l}\text { Unskillful/ } \\
\text { Skillful }\end{array}$ & +.14 & -.14 & -1.00 & 1.05 & 4.70 \\
\hline \multirow[t]{2}{*}{ The Dented Car } & $\begin{array}{l}\text { Guilty/ } \\
\text { Innocent }\end{array}$ & +1.36 & -.64 & -1.14 & $4.11 \S$ & 7.64 \\
\hline & $\begin{array}{l}\text { Angry/ } \\
\text { Ashamed }\end{array}$ & -1.93 & -.71 & +2.36 & $10.96 \dagger$ & 6.23 \\
\hline
\end{tabular}

would be reasonable to assume that the original Passage $A$ contained more adjectives than did the original Passage B. Similarly, an analogical case can be made that story versions with extreme angles contained more "visual adjectives" than story versions with neutral angles if the recall protocols from the extreme-angle versions contained significantly more adjectives than those from the neutralangle versions.

For this reason, the initial analysis of the recall data focused on the number of adjectives subjects used to describe the characters in the stories. Adjectives describing the characters' general physical (e.g., "large"), personal (e.g., "determined"), or emotional (e.g., "angry") characteristics were counted. Adjectives describing details of clothing or specific physical features-particularly describing color (e.g., "blue" dress or "blond" hair)and adjectives describing the background (e.g., "cold, snowy" day) were not counted. The number of adjectives describing characters photographed from an extreme angle (high or low) was then compared to the number of adjectives used to describe characters photographed from a neutral angle (eye-level). The mean number of adjectives in each story description was $4.53(S D=1.97)$ for extreme angle shots and $3.85(S D=2.03)$ for neutral angle shots. This difference was significant $[t(41)=3.30, p<.01]$.

Next, a second, more specific analysis of the recall protocols was conducted. The freely recalled descriptions of the two characters in each story were examined to determine whether camera angle influenced subjects' use of particular descriptive adjectives. That is, for each story, the frequency of occurrence of certain key adjectives was tabulated for each angle condition: low, eye-level, and high. Sets of adjectives were selected to reflect the potential influence of camera angle in the context of each particular story. Figure 4 illustrates the results of this second analysis of the recall data. Each data point represents the total number of occurrences of the specified key adjectives used to describe the two characters in each story. Given the design of this study, each data point sums over 28 character descriptions.

In four of the six stories, camera angle significantly influenced the use of key adjectives. Camera angle significantly affected the frequency with which subjects actually stated that the characters were (1) "small" $\left(\chi^{2}=12.66, p<.01\right)$ in "Boxes," (2) "stern," "firm," or "determined" $\left(\chi^{2}=10.70, p<.01\right)$ and "weak," "wimpy," or "timid" $\left(\chi^{2}=6.50, p<.05\right)$ in "The Smoker," (3) "tall" or "large" $\left(\chi^{2}=7.81\right.$, $p<.05)$ and "afraid," "scared," or "shy" $\left(\chi^{2}=6.00\right.$, $p<.05)$ in "Hitchhiker," and (4) "angry" or "mad" $\left(\chi^{2}=7.47, p<.05\right)$ and "guilty" $\left(\chi^{2}=9.50\right.$, $p<.01$ ) in "The Dented Car." (For all chi-square tests, $d f=2$ and $N=42$.)

A third analysis of the recall data focused more heavily on the extent to which camera angle affected the subjects' recall of the story lines. That is, can camera angle affect the gist of the picture stories, and in the predicted direction? Up until this point, the data analysis has examined how vertical camera angle can affect the evaluation or connotative meaning of the characters in the pic- 

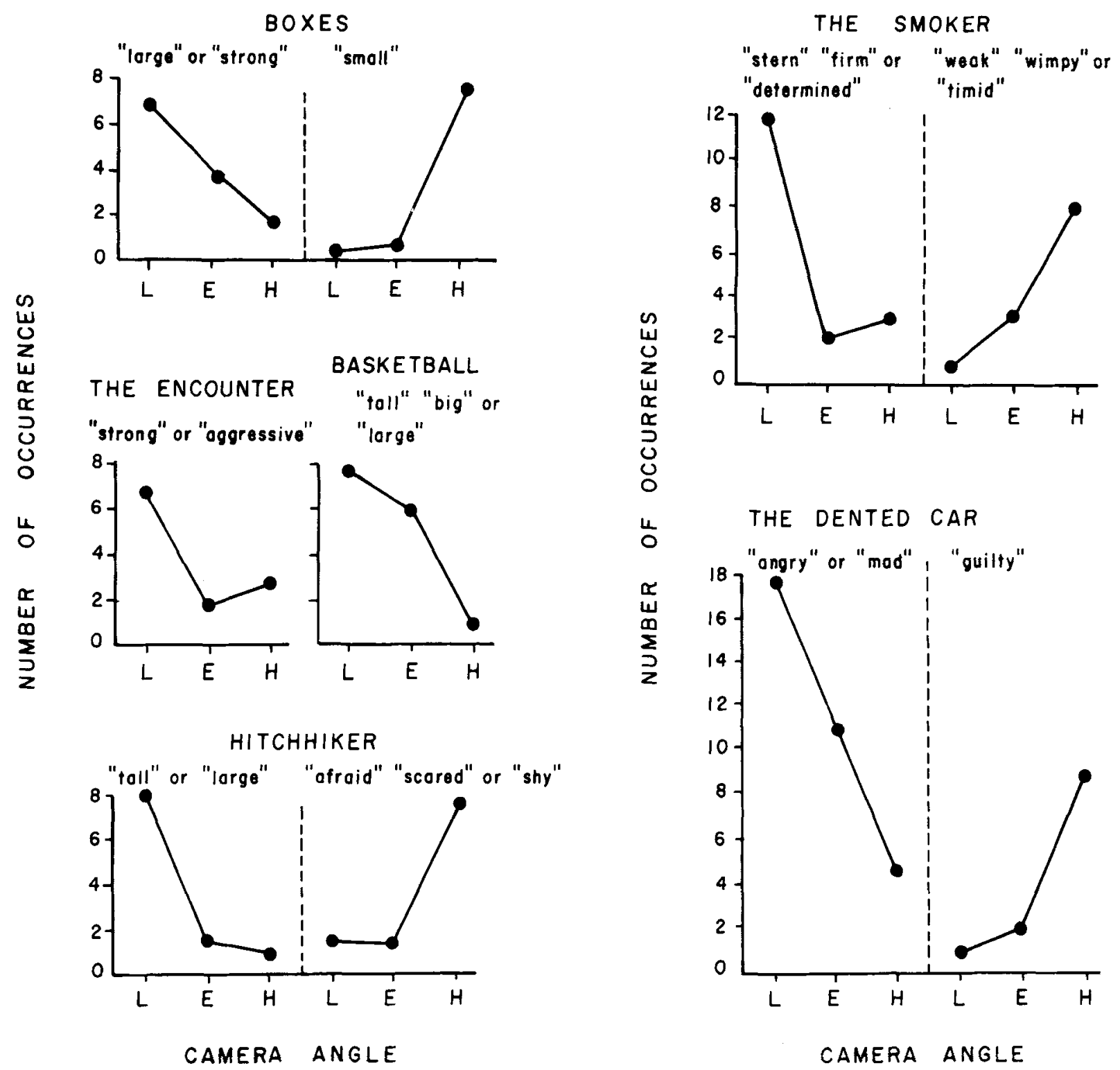

Figure 4. Number of occurrences of key adjectives used to describe the characters depicted from low (L), eye-level (E), and high (H) angles for each story.

ture stories. This next analysis focuses on how manipulations of camera angle can affect the causal structure or gist of the stories themselves. First, for each story, three ideal story lines were constructed, corresponding to the three slide versions of each story. That is, each story line was derived from the predicted effects of the camera angles within the context of a given story. The brief descriptions for the three versions of each story are presented in the left column of Table 2.

Six judges sorted the recall protocols for each story into three different categories, corresponding to the three story lines of each story shown in Table 2 . Thus, for a given story, the judges were told the three story lines and were required to categorize each recall protocol in terms of one of the three story lines. In addition, judges were instructed to create a fourth category for protocols that were informationally deficient.

The analysis of the judges' categorizations was conducted in the following manner. Each of the 42 subjects in Experiment 1 generated one recall protocol for each of the six target stories. After a judge sorted the 42 recall protocols for a given story into three story-line categories (Table 2), each story-line category was analyzed separately by recording the number of Version 1 protocols, Version 2 protocols, and Version 3 protocols sorted into that story-line category. For example, first, Judge A sorted the 42 protocols from the story "Boxes" into three story-line categories. Next, the Story-line 1 category was analyzed by recording the number of subjects within Judge A's Story-line 1 category who were 
Table 2

Story-Line Descriptions and Analysis of Judges' Story-Line Categorizations of the Free Recall Protocols of Experiment 1

Ideal Story Lines
BOXES
1. The boxes were large and in the woman's way.
2. The boxes were a slight hindrance to the woman.
3. The boxes were small and not in the woman's
way.

\section{THE ENCOUNTER}

1. The male doll was trying to attract the female doll; the female doll was afraid.

2. Both dolls were interacting on equal terms.

3. The female doll was trying to attract the male doll; the female doll was unafraid.

\section{THE SMOKER}

1. The woman requested that the man stop smoking, but the man stood firm.

2. The woman requested that the man stop smoking, but it was not clear if he stopped.

3. The man wanted to continue smoking, but the woman stood firm, refusing to let him smoke.

\section{HITCHHIKER}

1. The driver was aggressive, and the hitchhiker was hesitant to enter the car.

2. The driver picked up the hitchhiker with no problems.

3. The hitchhiker was aggressive, and the driver was hesitant to pick him up.

\section{BASKETBALL}

1. The defense man was larger and probably prevented the basket.

2. Both players were of equal ability. It was difficult to determine the final outcome.

3. The ball handler was larger and probably ended up scoring the basket.

\section{THE DENTED CAR}

1. The man was guilty of denting the woman's car, and the woman was angry.

2. Neither the man nor the woman was responsible for the dented car.

3. The woman was guilty of denting the man's car, and the man was angry.

*The $d f$ for all $F$ tests $=2,10, \quad t p<.001, t p<.05$

Mean Proportion of Responses in Each Story-

Line Category Contributed by Subjects from the Three Story Versions

\begin{tabular}{|c|c|c|c|}
\hline Version 1 & Version 2 & Version 3 & $F$ Value* \\
\hline Boxes: Low & Eye & High & \\
\hline Woman: High & Eye & Low & \\
\hline .34 & .32 & .34 & .074 \\
\hline .28 & .37 & .35 & 1.59 \\
\hline .35 & .32 & .32 & .036 \\
\hline Male: Low & Eye & High & \\
\hline Female: High & Eye & Low & \\
\hline .33 & .31 & .35 & .453 \\
\hline .31 & .39 & .29 & 2.69 \\
\hline .45 & .13 & .42 & $15.66 \dagger$ \\
\hline Man: Low & Eye & High & \\
\hline Woman: High & Eye & Low & \\
\hline .46 & .22 & .32 & $6.70 \ddagger$ \\
\hline .33 & .28 & .38 & 2.22 \\
\hline .24 & .45 & .30 & $8.73 \S$ \\
\hline Driver: Low & Eye & High & \\
\hline Hitcher: High & Eye & Low & \\
\hline .44 & .33 & .23 & $21.17+$ \\
\hline .27 & .37 & .36 & $10.20 \S$ \\
\hline .08 & .00 & .92 & $8.79 \S$ \\
\hline Defense: Low & Eye & High & \\
\hline Offense: High & Eye & Low & \\
\hline .50 & .27 & .23 & 3.64 \\
\hline .26 & .47 & .27 & $19.02 \dagger$ \\
\hline .43 & .07 & .50 & $28.25 \dagger$ \\
\hline Woman: Low & Eye & High & \\
\hline Man: High & Eye & Low & \\
\hline .72 & .20 & .08 & $265.95 \dagger$ \\
\hline .23 & .54 & .24 & $59.08 \dagger$ \\
\hline .10 & .16 & .74 & $130.05 \dagger$ \\
\hline
\end{tabular}

originally shown Boxes-Version 1, the number who were originally shown Boxes-Version 2, and the number who were originally shown Boxes-Version 3 . Thus, each judge was assigned three numbers for a given story-line categorization. Judges sorted the descriptions one story at a time, and each story was tabulated separately. After all six judges sorted the recall protocols into story-line categories for each story, one-way within-judges analyses of variance with three levels (number of Version 1 protocols vs. number of Version 2 protocols vs. number of Version 3 protocols) were conducted.

To reveal overall story-line effects, an initial examination of the data was carried out by collapsing over stories. Figure 5 illustrates the general pattern of results. For clar- 


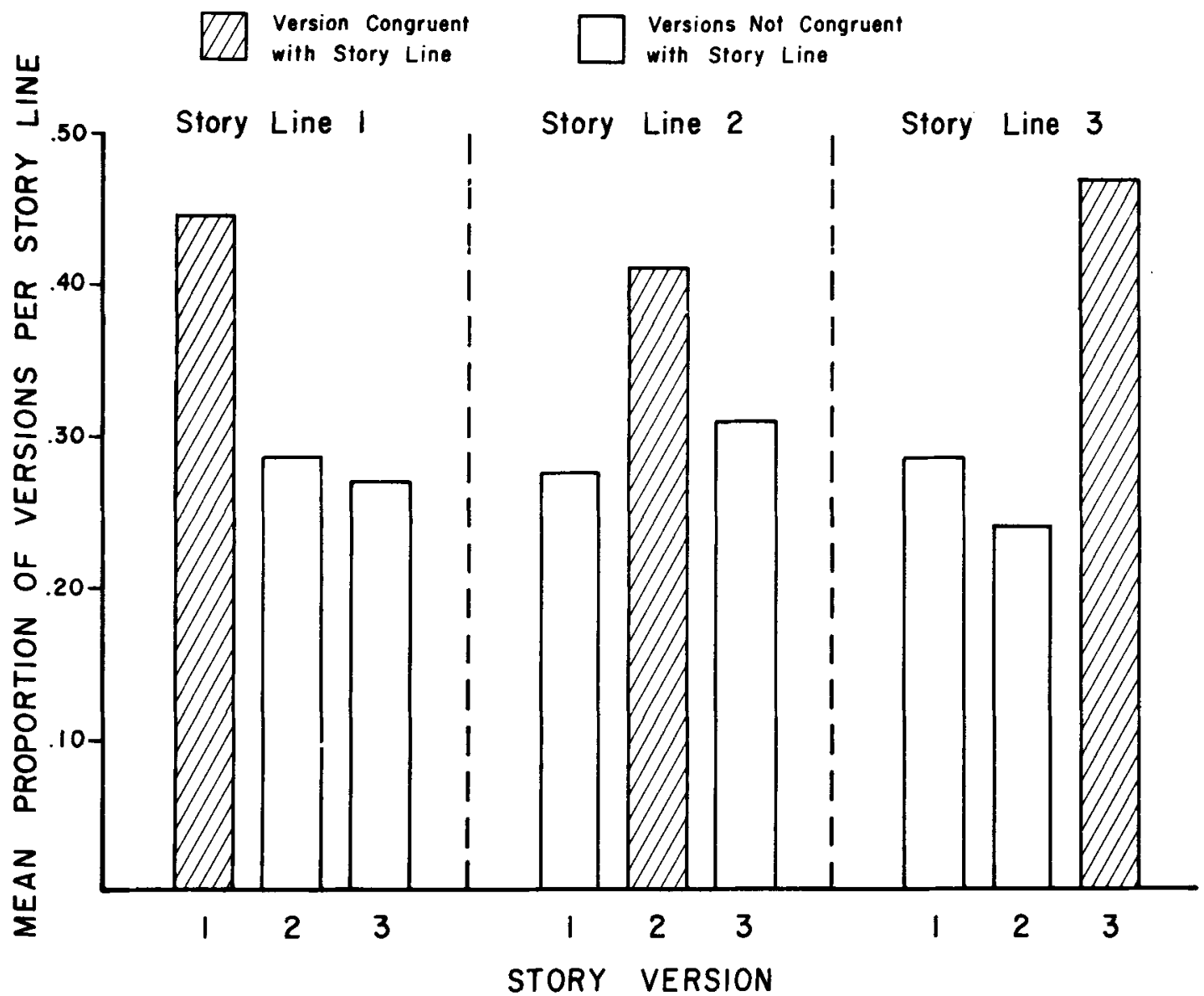

Figure 5. Mean proportion of protocols in each story-line category from the three story versions.

ity of presentation, Figure 5 shows the mean proportion of protocols in each story-line category from the story versions; all statistical analyses were conducted on the actual number of protocols sorted into each story-line category. According to the judges' categorizations, camera angle significantly affected subjects' recall of the stories in the predicted direction for all three story lines. Story-line 1 descriptions came primarily from Version 1 subjects $[F(2,10)=27.99, M S e=13.26, p<.001]$; Story-line 2 descriptions came primarily from Version 2 subjects $[F(2,10)=22.04, M S e=18.45, p<.001]$; Story-line 3 descriptions came primarily from Version 3 subjects $[F(2,10)=18.46, M S e=12.90, p<.001]$. Camera angle significantly affected the narrative relationship between the two characters in each story so that the actual plots or causal structure of the stories themselves were altered-with predictable results.

To reveal specific recall patterns for each story, separate analyses were conducted. Table 2 illustrates the results of the judges' story-line categorizations for each of the six target stories. Three of the six stories showed significant effects of camera angle in the predicted direction on at least two of the judges' story-line categories, and two of the six stories-"Hitchhiker" and "The Dented Car"showed significant effects of camera angle in the predicted direction on all three of the story-line categories. "The
Encounter" produced only one significant effect of camera angle, and "Boxes" did not show any.

The above analysis of the recall data demonstrates that manipulations of vertical camera angle can affect the gist of picture stories. For instance, in "The Dented Car," Version 1 (woman-low, man-high) led subjects to recall that the woman was angry and that the man was guilty of denting the woman's car. Version 3 (woman-high, man-low) led subjects to recall that the man was angry and that the woman was guilty of denting the man's car. And Version 2 (woman-eye-level, man-eye-level) led subjects to recall that the man and the woman were equally innocent. Manipulations of vertical camera angle also affected in a similar manner the recall of gist with "The Smoker," "Hitchhiker," and "Basketball." Camera angle, however, was not equally effective across all the picture stories in influencing subjects' memory representations of these stories. The following discussion accounts for the relative effectiveness and ineffectiveness of camera angle specific to the six target stories in Experiment 1. A discussion of general theoretical issues is presented following Experiment 3.

Why did camera angle work reliably in most stories but have no effect in others? One variable that may influence viewers' sensitivity to camera angle is the appropriateness of the formal manipulation to the characters and the 
plot of the story. With "Basketball," the narrative relationship between the two characters was closely tied to their relative heights. In the context of a one-on-one basketball game (as in the story "Basketball"), the taller player has the advantage over the smaller player, and, thus, because changes in vertical camera angle strongly affected the judged heights of the basketball players, the relative success of the two players (ball handler scoring vs. defense man preventing the basket) was also affected by such changes. In the context of a confrontation, such as hitchhiking ("Hitchhiker") or telling another person to put out his cigarette ("The Smoker"), size, strength, bravery, boldness, and aggressiveness are important qualities. Since changes in vertical camera angle affected subjects' judgments of these qualities, the relative success of the confronting characters was affected, as was the story line.

A second variable that may influence viewers' sensitivity to compositional manipulations is the strength of the narrative context in specifying the character relationships and the story line. For instance, in Experiment 1, the story with the least contextual glue was "The Dented Car," which was also the story that was most sensitive to the effects of camera angle. Subjects were shown two shots of a dented car (a medium shot and a close-up) followed by a medium shot of a woman and a medium shot of a man. There was no spatial overlap between the two set-up shots and the character shots, and there was no theme depicted to connect the set-up shots with the two characters. Furthermore, there was no identifiable commonality between the two characters themselves other than simple juxtaposition. It appears, then, that subjects will use whatever information is available to make the story cohere; the less narrative information provided by the characters and setting, the more the compositional information will influence the subjects' representations of the stories. This argument does not claim that camera angle is ineffective in influencing stories with strong narrative structure; it says that with strongly specified plots, camera angle will enhance the visual message when used appropriately and will weaken the message when used inappropriately. One reason the plot structure of "Boxes" was relatively unaffected by camera angle was that the characters and activities were strongly specified by the subject matter. There was little ambiguity that the woman was hindered by a pile of boxes in her way. A close inspection of the recall protocols from "The Encounter" also indicates the same kind of effect; few subjects comprehended the event as being dominated by the female doll, regardless of camera angle.

In general, camera angles act as visual adjectives, providing viewers with cues not only about the physical, personal, and emotional characteristics of the characters in a given story, but also, through manipulations of connotative meaning, about the narrative relationships between these characters.

Recognition performance. For the content discrimination task, the mean hit rate was $.99(S D=.03)$ and the mean false alarm rate was $.01(S D=.10)$; for the angle discrimination task, the mean hit rate was .87
$(S D=.14)$ and the mean false alarm rate was .31 $(S D=.22)$. For each subject, $d^{\prime}$ scores were computed for discrimination of old and new content slides and for discrimination of old and new angle slides. The mean $d^{\prime}$ score was $4.50(S D=.32)$ for the content discrimination task and $2.09(S D=1.01)$ for the angle discrimination task. Although performance on the angle discrimination task was significantly better than chance $[t(41)=$ $13.35, p<.001]$, it was appreciably poorer than performance on the content discrimination task $[t(41)=$ $15.14, p<.001]$. Subjects easily discriminated old and new characters and objects, but had considerably more difficulty discriminating old and new camera angles. This pattern of memory for gist and form with pictorial materials is similar to the pattern with verbal materials (Glucksberg \& Danks, 1975; Sachs, 1967; Soli \& Balch, 1976). Sachs (1967) demonstrated that subjects remember the meaning of individual sentences within a larger context but do not retain the syntactic form of these sentences. Similarly, in this experiment, subjects' representations of the pictorial events primarily contained information about content, not about form. Also, as in Soli and Balch (1976), although formal information was remembered more poorly than was semantic information, recognition performance with formal information was significantly above chance. The major functional difference here is that the formal changes in camera angle served a rhetorical function, not a syntactic one (Corbett, 1971). Changes in camera angle shaped the connotative meaning of the narrative elements and the overall gist of the pictorial events.

The final analysis involved a direct correlation between the connotative influence of camera angle and recognition memory for camera angle. On each rating scale for each subject, the mean rating for high-angle shots was subtracted from the mean rating for low-angle shots. These individual difference scores were then summed across the rating scales to yield a single, composite difference score for each subject. Subjects' difference scores were then correlated with their $d^{\prime}$ scores on the angle recognition task. In this way, it was possible to compare directly the extent to which each subject was influenced by camera angle and the accuracy with which that subject recognized camera angle. The correlation coefficient was -.231 , which was not significantly different from zero $[t(40)=1.50, p>.05]$. Nonetheless, the negative correlation suggests that subjects who were most influenced by camera angle on the evaluation task were least able to remember angle on a subsequent recognition test.

In general, it can be stated that vertical camera angle has significant, predictable effects on judgments made about the physical and personal characteristics of characters in picture stories, on the recall of these characteristics, and on the recall of the gist of the stories themselves. Yet, recognition memory for camera angle is significantly less accurate than recognition memory for content. Subjects use the information available to them in order to con- 
struct consistent, coherent representations of the picture stories; and although vertical camera angle can be an important influence in the construction of these representations, once the story representation is constructed, specific camera angle information becomes less accessible.

One problem with drawing conclusions from the recall data of Experiment 1, however, is that the initial rating task may have been a reactive measure, influencing subjects' recall of the target stories. For instance, it may be the case that after viewing "The Dented Car," subjects may not have voluntarily recalled information about the characters' guilt or innocence had they not previously filled out an innocent-guilty rating scale. In order to control for this potential confound, Experiment 2 was conducted in which the subjects performed the recall task prior to any rating task. The critical dependent measures in Experiment 2 to reveal the reactivity of the rating task were the subjects' use of adjectives in the free recall task and the subjects' cued recall of different story lines for a given story.

Another reason for conducting Experiment 2 that required the subjects to recall the stories before rating the characters was to determine whether vertical camera angle would retain its influence on the subjects' ratings of the characters even after the 20- to 25 -min recall task. If camera angle can still influence the subjects' ratings after such an interval, a stronger case can be made for the notion that information concerning a character's height, strength, or boldness is part of the subjects' representations of the stories. In Experiment 1, subjects filled out the rating scales immediately after viewing each story, and it may be the case that the information tapped by the rating scales would fade soon after the stories were presented.

A third reason for conducting Experiment 2 was that it presented an opportunity to add some specific cuedrecall questions after the free recall of each story to tap more precisely the subjects' recall of the story line. That is, instead of requiring several judges to categorize the story lines, subjects would indicate directly which story line they had observed.

\section{EXPERIMENT 2}

The primary goal of Experiment 2 was to determine whether vertical camera angle could predictably and significantly affect subjects' recall of picture stories without the interposition of a rating task between presentation and recall of the stories. Second, Experiment 2 was conducted to determine whether the results obtained from the immediate rating task in Experiment 1 could be replicated with a delayed rating task. Third, a cued-recall task was added to the free-recall task in order to indicate more directly the particular story line that each subject recalled.

\section{Method}

Subjects. Thirty-six students enrolled in the introductory psychology course at Grinnell College served as subjects. Subjects were run in three groups of 12 .
Materials. Experiment 2 employed the same materials as Experiment 1 .

Procedure. Subjects performed four separate tasks with the stories. (1) After each target story was presented, subjects were given $3 \mathrm{~min}$ and $20 \mathrm{sec}$ to engage in a free-recall task. (2) After the free-recall task was completed for the entire set of stories, subjects answered a set of brief cued-recall questions. (3) After the cued-recall task, subjects were given approximately $8 \mathrm{~min}$ to rate the characters in the stories along a variety of 7 -point rating scales. For the cued-recall task and the rating tasks, the stories were tested in their original order. (4) After the rating task, subjects participated in a recognition test. The free-recall task, the rating task, and the recognition test were identical to those in Experiment 1 . The cued-recall task consisted of questions specific to the plot of each story; the set of questions is presented in the Appendix. The design for presentation of the stories and the recognition sequence was the same as in Experiment 1.

\section{Results and Discussion}

Recall data. First, the number of adjectives used by subjects in Experiment 2 was compared to the number in Experiment 1. Subjects in Experiment 2 averaged 14.1 $(S D=8.24)$ adjectives, whereas subjects in Experiment 1 averaged $25.8(S D=11.34)$ adjectives. This difference was significant $[t(76)=5.28, p<.001]$, suggesting that the task of rating characters in Experiment 1 may have stimulated subjects to use more adjectives in the free-recall task.

Next, as in Experiment 1, for each story, the number of key story-specific adjectives was tabulated for each angle condition: low, eye-level, and high. The number of such adjectives was appreciably lower, however, and the focus was not as sharp. Because subjects had not been exposed to the adjective-based rating scales, they were less likely to use adjectives in general, and those they did use were more varied. To accommodate this smaller and more diverse set of responses, the range of key adjectives in Experiment 2 was expanded, although the connotative meanings supported by these adjectives were similar to those of Experiment 1. Table 3 shows the results of this analysis. With two of the stories ("The Smoker" and "Hitchhiker"), even without exposure to a prior evaluation task, subjects freely described the characters in accordance with the ideal story lines (Table 2). Clearly, however, subjects were less forthcoming in their use of key adjectives. The act of evaluating characters along rating scales may have stimulated more evocative and more focused descriptions. It is also possible that the task of recalling the events immediately after each story was presented may have placed less emphasis on distinguishing actors in one story from those in another, thereby producing fewer comparative adjectives than the recall task in Experiment 1.

Cued-recall data. The answers to the cued-recall questions were analyzed to determine the effect of camera angle on subjects' representations of the story lines. Answers were categorized in accordance with the ideal story lines presented in Table 2. For example, after viewing "The Dented Car," if a subject answered Question 6 (see Appendix) by indicating that the man hit the woman's car, 
Table 3

Frequency of Key Adjectives as a Function of Camera Angle in Experiment 2

\begin{tabular}{|c|c|c|c|c|c|}
\hline Story & Key Adjectives & Low & Eye-Level & High & $x^{2}$ \\
\hline BOXES & "tall" or "large" & 5 & 3 & 1 & 2.66 \\
\hline THE ENCOUNTER & $\begin{array}{l}\text { Threatening ,, "ominous," } \\
\text { ("menacing," "'oming," } \\
\text { "threatening, or } \\
\text { "intimidating," or } \\
\text { "arrogant") }\end{array}$ & 4 & 1 & 2 & 1.99 \\
\hline \multirow[t]{2}{*}{ THE SMOKER } & $\begin{array}{l}\text { Rude } \\
\text { ("uncaring,", } \\
\text { inconsiderate," } \\
\text { or "arrogant") }\end{array}$ & 7 & 0 & 1 & $10.74 *$ \\
\hline & 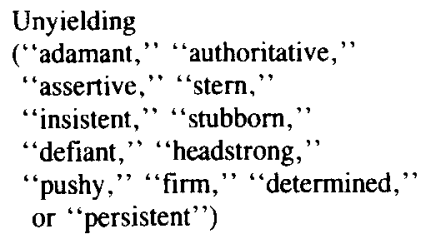 & 9 & 6 & 6 & 1.67 \\
\hline \multirow[t]{2}{*}{ HITCHHIKER } & $\begin{array}{l}\text { Dangerous } \\
\text { ("devious," “intimidating," } \\
\text { "sinister," or "evil") }\end{array}$ & 6 & 1 & 0 & $8.85 \dagger$ \\
\hline & $\begin{array}{l}\text { Reticent } \\
\text { ("hesitant," "nervous,", } \\
\text { "not eager," "unsure," } \\
\text { "afraid," "undecided," } \\
\text { "fearful," or "timid") }\end{array}$ & 1 & 3 & 8 & $6.50 \dagger$ \\
\hline BASKETBALL & "tall" or "large" & 4 & 2 & 2 & 1.00 \\
\hline THE DENTED CAR & $\begin{array}{l}\text { "mad," "angry," or } \\
\text { "indignant" }\end{array}$ & 8 & 4 & 3 & 2.80 \\
\hline
\end{tabular}

${ }^{*} p<.01 . \quad+p<.05$.

that subject would be scored as having recalled Storyline 1. After the subjects' answers were scored with respect to story line, the number of congruent and noncongruent versions was recorded for each subject. For example, if a subject originally viewed Version 1 of "The Dented Car" and then recalled that the man hit the woman's car (Story-line 1), the version would be scored as congruent with that story line. If that subject recalled Story-line 1 after having viewed Version 2, however, the version would be scored as incongruent with the recalled story line. The mean number of congruent answers per subject was $2.53(S D=.97)$. A one-sample $t$ test showed that the number of congruent versions was significantly better than chance $[t(35)=3.26, p<.01]$, demonstrating that vertical camera angle had a small but significant influence in the appropriate direction on subjects' answers to specific questions about the gist of the stories.

Rating data. A second reason for conducting Experiment 2 was to determine whether vertical camera angle could influence the subjects' ratings of the characters even after a lengthy recall task. Figure 6 summarizes the results from the delayed rating task for the six common rating scales, collapsed over the different characters in the target stories. There was a significant main effect of vertical camera angle in the predicted direction with three of the six scales, using a one-way within-subjects analysis of variance with three levels. The following three scales showed significant main effects of angle: (1) short/tall $[F(2,70)=3.78, M S e=.470, p<.05] ;(2) \mathrm{timid} /$ bold $[F(2,70)=3.53, M S \mathrm{e}=.396, p<.05]$; and (3) passive/aggressive $[F(2,70)=6.19, M S e=.494$, $p<.01]$. Camera angle did not significantly affect subjects' ratings on the weak/strong scale $[F(2,70)=2.41$, $M S e=.547, p<.10]$, the afraid/unafraid scale $[F(2,70)$ $=.569, M S \mathrm{e}=.464, p>.25]$, or the good/bad scale $[F(2,70)=1.36, M S \mathrm{e}=.287, p>.25]$. (The $S D$ s for the means shown in Figure 6 ranged from .53 to .88 ). In general, as one changes from a high-angle shot to an eye-level shot to a low-angle shot, the characters in these shots are represented as being taller, bolder, and more aggressive. These characteristics are part of the subjects' representations even after a lengthy recall task.

Recognition performance. For the content discrimination task, the mean hit rate was $.98(S D=.06)$ and the mean false alarm rate was $.003(S D=.02)$; for the angle discrimination task, the mean hit rate was .83 $(S D=.12)$ and the mean false alarm rate was .31 $(S D=.24)$. As in Experiment 1, there was a highly significant difference between subjects' ability to discriminate old- and new-content slides and their ability to discriminate old- and new-angle slides $[t(35)=15.90$, $p<.001]$. The mean $d^{\prime}$ score was $4.48(S D=.47)$ for the content discrimination task and $1.81(S D=1.15)$ for the angle discrimination task. Performance on the angle 


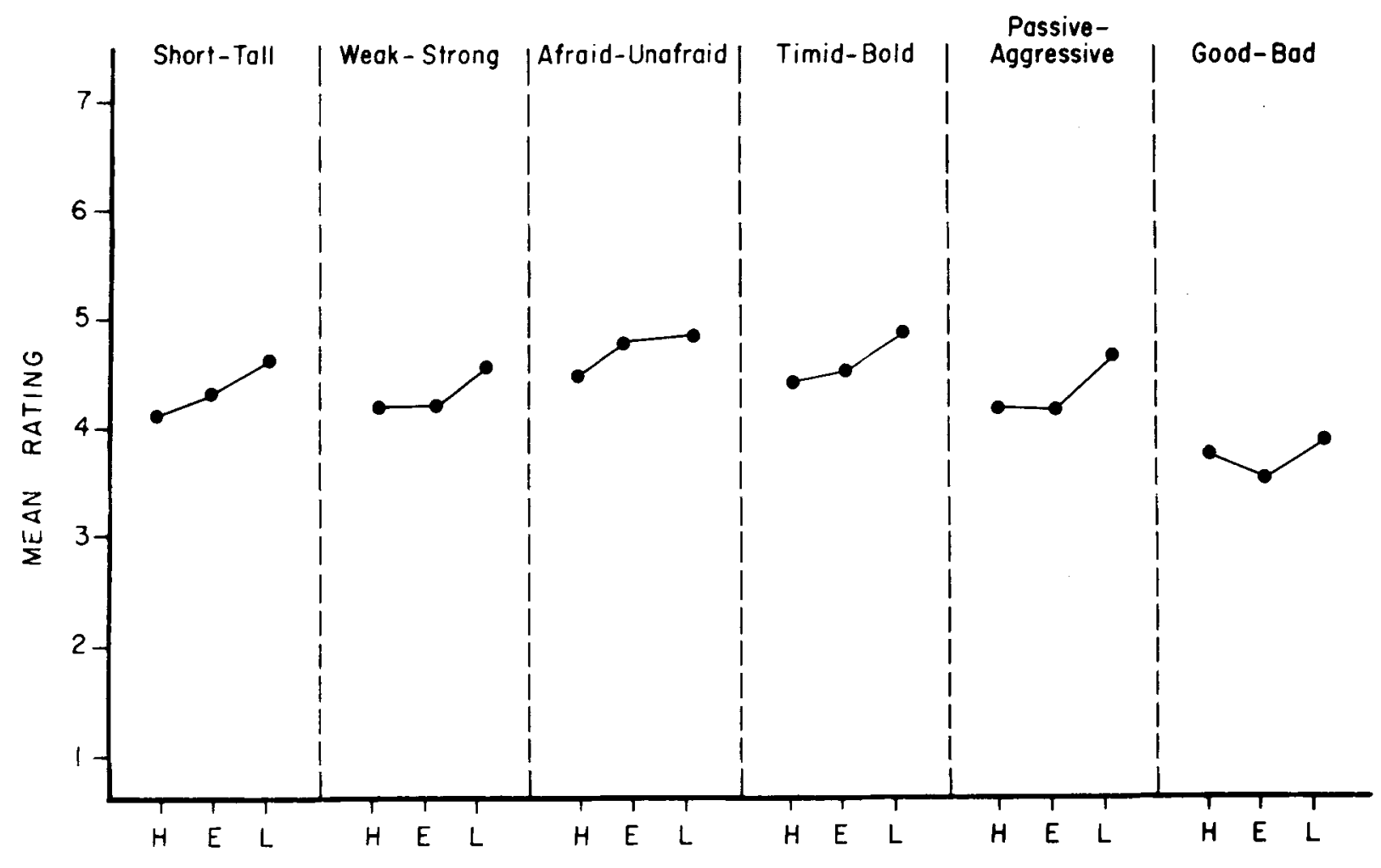

CAMERA ANGLE

Figure 6. Connotative meaning as a function of three vertical camera angles: (1) high (H), (2) eye-level (E), and (3) low (L) in Experiment 2.

discrimination task was better than chance $[t(35)=9.41$, $p<.001]$.

In general, Experiment 2 demonstrated that the act of rating the characters in the picture stories may serve to guide the subsequent recall of the stories in accordance with the adjectives used on the rating scales, highlighting particular features of the narrative representations. The significant difference between Experiments 1 and 2 regarding overall adjective use and the weaker results in Experiment 2 concerning the use of key adjectives support this conclusion. As indicated by the results of the cued-recall task, however, camera angle maintained its effect on recall of the general gist of the stories. Moreover, even after a considerable length of time, camera angle maintained its influence over subjects' evaluations of the characters in the stories, as indicated by the results from the rating scales.

Experiment 2 also replicated the findings of the recognition portion of Experiment 1: changes in camera angle are significantly more difficult to detect than are changes in content on a recognition test. One problem, however, with the hypothesis that information derived from vertical camera angle has its effect on connotative meaning judgments and recall and then becomes less accessible is that the recognition tests were conducted subsequent to the rating tasks and the recall tasks in Experiments 1 and
2. Information concerning camera angle may have been available soon after the picture stories were presented, but may have decayed at a faster rate than other types of information. In order to assess recognition memory for vertical camera angle immediately following presentation of the stories, Experiment 3 was conducted.

\section{EXPERIMENT 3}

The primary goal of Experiment 3 was to determine the extent to which subjects can recognize changes in vertical camera angle immediately after viewing picture stories in which camera angle is manipulated. The specific concern of Experiment 3 was to eliminate the 20-min interval between termination of the presentation sequence and onset of the recognition test which existed in Experiment 1 . Pilot work revealed that if the presentation sequence was presented straight through with no time between stories, recognition of vertical camera angle was actually poorer than in Experiment 1 . Such a manipulation may be an unfair control against which to compare delayed recognition because it gives the subjects no opportunity to process each story: Thus, in Experiment 3, in order to assess immediate recognition memory for vertical camera angle and still give subjects an opportunity to think about each story as they did in Experiment 1, sub- 
jects were allowed to evaluate the characters in the stories along the rating scales, exactly as they did in Experiment 1 .

\section{Method}

Subjects. Twenty-four subjects enrolled in the introductory psychology course at Grinnell College served as subjects. Subjects were run in three groups of 8 .

Materials. Experiment 3 employed the same materials as Experiments 1 and 2 .

Procedure and Design. The picture stories and the recognition test were presented to all subjects in the same manner as they were presented in Experiments 1 and 2. The recognition test was administered immediately following presentation of the stories. The design consisted of one within-subjects manipulation (angle discrimination vs. content discrimination). Of primary interest was the recognition task.

\section{Results and Discussion}

For the content discrimination task, the mean hit rate was $.96(S D=.11)$ and the mean false alarm rate was $.02(S D=.05)$; for the angle discrimination task, the mean hit rate was $.81(S D=.21)$ and the mean false alarm rate was $.33(S D=.17)$. As in the previous experiments, subjects were significantly better at discriminating old- and new-content slides than they were at discriminating old- and new-angle slides $[t(23)=9.02$, $p<.001]$. The mean $d^{\prime}$ score was $4.19(S D=.95)$ for the content discrimination task and $1.75(S D=1.11)$ for the angle discrimination task. Moreover, recognition performance in Experiment 3 was not significantly better than in Experiment 1 for either the content discrimination task $[t(64)=1.54, p>.10]$ or the angle discrimination task $[t(64)=1.20, p>.20]$. The comparatively poor performance in discriminating old and new angles was not due simply to the passage of time or to the presence of an intervening task.

\section{GENERAL DISCUSSION}

The general finding of these experiments is that camera angle can profoundly affect the meaning viewers ascribe to pictorial events. Experiment 1 demonstrated that vertical camera angle can have significant, predictable effects on judgments made about the physical and personal characteristics of characters in picture stories and on the recall of the stories themselves. Futhermore, recognition memory for the actual camera angles was significantly less accurate than memory for content. Experiment 2 demonstrated that the task of evaluating the characters in the stories enhanced the effect of camera angle, as indicated by free-recall descriptions of the characters. A subsequent cued-recall task showed that vertical camera angle can predictably and significantly affect memory for the characters and the stories even in the absence of a prior rating task. Experiment 2 also demonstrated that vertical camera angle can affect subjects' evaluations of the characters even after a considerable delay, indicating that the information present in the rating scales was part of the subjects' representations of the picture stories. As in
Experiment 1, recognition memory for camera angle in Experiment 2 was comparatively inaccurate. Experiment 3 showed that the low recognition performance for camera angle was not an artifact of the designs of Experiments 1 and 2; an immediate recognition task produced recognition performance as inaccurate as in the previous experiments.

The source of camera angle effects may lie in our experience with the natural visual world. The meanings associated with each different camera angle, rather than resulting from film literacy or learned convention, may be derived from the actual visual relationships between the viewers and the depicted characters. For example, a low-angle shot forces the viewer to look up at the actors, placing the actors in a position of visual authority and dominance. An eye-level shot places the viewer face-toface with the actors, producing visual parity. A high-angle shot allows the viewer to look down on the actors, providing a higher vantage point and placing the viewer in a position of visual dominance. These physical relationships between camera and actor may engender a particular connotative meaning, either via some sort of metaphorical operation or via a more direct, literal perception of that connotative meaning. Film theorists (e.g., Andrew, 1976; Coynik, 1974; Giannetti, 1982; Kracauer, 1960; Mascelli, 1965; Metz, 1974; Monaco, 1981; Spottiswoode, 1967) generally agree that connotative meanings associated with camera angles are derived from a simple analogical operation, translating a spatial relationship into an evaluative one. For example, physically looking down at an actor translates into looking down on that actor; physically looking up at an actor translates into looking up to that actor.

An alternative hypothesis would be that there is different information available in shots taken from different angles, and that this information is directly available without any sort of analogical translation. The major arguments of this hypothesis are as follows: (1) Pictures of the same subject matter taken at different vertical camera angles provide different information to the viewer. (2) The critical informational difference between pictures varying only with respect to vertical camera angle concerns what the pictures afford the viewer (Gibson, 1979). That is, by changing vertical camera angle, one changes the reallife consequences of the pictured scene. For example, a low-angle shot of a given character puts the viewer into the scene on the floor, looking up at that character. And, being on the floor, looking up at a character affords different things from being over the character and looking down on him, as in a high-angle shot. The meaning of one shot is different from the meaning of the other because the affordance structure is different. (3) Of paramount importance in the viewers' comprehension and retention of representational pictorial materials are the real-life consequences of the pictured scenes (Gibson, 1979; Kraft \& Jenkins, 1977, 1979; Mandler \& Johnson, 1976; Mandler \& Ritchey, 1977). Thus, any compositional manipulations, such as manipulations of camera angle, which alter the real-life consequences of a pictured scene, should affect the viewers' comprehension and memory for these 
scenes. The connotative meanings derived from natural visual experience are woven into the story lines.

The present experiments did not distinguish empirically the two hypothesized operations allegedly involved in associating different meanings with each type of vertical camera angle. Rather, the experiments described above represent an empirical demonstration of the effects of manipulating vertical camera angle. Future research will be needed to provide insights into the processes involved with these demonstrated effects. There are several approaches for examining more closely the extent to which viewers directly perceive the characters in low-angle shots as being taller or stronger or bolder than characters in high-angle shots. First, subjects could be asked more precise questions about the height of the characters, the position of the camera, and the position that they themselves occupied while viewing the stories. Second, finer, more precise changes in camera angle could be made in order to quantify the relationship between camera angle and judgments of height, boldness, strength, and so on. Third, the nature of the confusions on the recognition test could be examined to determine where viewers thought they were positioned at given points in the picture stories. In general, more research is needed to document the psychological validity of other compositional manipulations such as manipulations of lighting, lines, perspective, framing, and balance in a narrative context.

One area of visual communication to which the power of psychologically effective photographic techniques can be applied is advertising. Since readers typically attend to advertisements for a very short period of time, the appropriate connotations must be conveyed very quickly. To do so, advertisers must be capable of visual communication as well as verbal. In order to construct effective visual messages, then, advertisers need to be aware of visual techniques that have predictable psychological effects. Another area, related to advertising, to which psychological research on compositional principles can be applied is consumer protection. If advertisements can visually persuade the viewer, they can also visually deceive. There are documented methods for detecting verbal deception, but not for detecting visually mediated deception. Further investigations into the psychological reality of photographic techniques can thus help to codify and elaborate principles of visual communication for the purpose of assessing the visual content of commercial messages.

A rudimentary form of attribution theory (e.g., Schachter \& Singer, 1962) provides a more general emphasis to the results obtained in these experiments. Because the form of a shot can profoundly affect viewers' attitudes toward the characters depicted in that shot, and because information about form is not as salient in the memory representation as information about the characters, viewers may attribute their formally derived attitudes to the characters themselves. The viewers' memorial in- sensitivity to particular formal techniques may empower these techniques with more potency than they might otherwise have.

\section{REFERENCES}

Alwit, L. F., ANDerson, D. R., LoRCh, E. P., \& LeVIn, S. R. (1980). Preschool children's visual attention to attributes of television. $\mathrm{Hu}$ man Communication Research, 7, 52-67.

ANDERson, D. R., \& SMTth, R. (1984). Young children's TV viewing: The problem of cognitive continuity. In F. J. Morrison, C. Lord, \& D. P. Keating (Eds.), Applied developmental psychology (pp. 115-163). New York: Academic Press.

ANDREW, J. D. (1976). The major film theories. New York: Oxford University Press.

ARNheim, R. (1974). Art and visual perception. Berkeley: University of California Press.

BAGGETT, P. (1975). Memory for explicit and implicit information in picture stories. Joumal of Verbal Learning \& Verbal Behavior, 14, 538-548.

BAGGETT, P. (1979). Structurally equivalent stories in movies and text and the effect of the medium on recall. Joumal of Verbal Learning \& Verbal Behavior, 18, 333-356.

BALL, V. K. (1965). The aesthetics of color: A review of fifty years of experimentation. Joumal of Aesthetics \& Art Criticism, 23, 441-452.

Carroll, J. M., \& BeVER, T. G. (1976). Segmentation in cinema perception. Science, 191, 1053-1055.

Chandler, A., Barnhart, E. (1938). A bibliography of physiological and experimental esthetics. Berkeley: University of California Press.

CORBETT, E. P. J. (1971). Classical rhetoric for the modem student. New York: Oxford University Press.

CoYnIK, D. (1974). Movie making. Chicago: Loyola University Press.

CraIK, F. I. M., \& LoCkHART, R. S. (1972). Levels of processing: A framework for memory research. Journal of Verbal Learning \& Verbal Behavior, 11, 671-684.

Eisenstein, S. (1949). Film form. New York: Harcourt, Brace.

Giannetrı, L. D. (1982). Understanding movies. Englewood Cliffs, NJ: Prentice-Hall.

GiBson, J. J. (1979). The ecological approach to visual perception. Boston: Houghton Mifflin.

GluCKSBERG, S., \& DANKS, J. H. (1975). Experimental psycholinguistics: An introduction. Hillsdale, NJ: Erlbaum.

HeVNer, K, (1935). Experimental studies of the affective value of colors and lines. Journal of Applied Psychology, 19, 385-398.

HochberG, J. (1978). Art and perception. In E. C. Carterefte \& M. P. Friedman (Eds.), Handbook of perception: Vol. 10. Perceptual ecology (pp. 225-258). New York: Academic Press.

HOCHBERG, J., \& BROoks, V. (1978a). Film cutting and visual momentum. In J. W. Senders, D. F. Fisher, \& R. A. Monty (Eds.), Eye movements and the higher psychological functions (pp. 293-313). Hillsdale, NJ: Erlbaum.

HOCHBERG, J., \& Brooks, V. (1978b). The perception of motion pictures. In E. C. Carterette \& M. P. Friedman (Eds.), Handbook of perception: Vol. 10. Perceptual ecology (pp. 259-304). New York: Academic Press.

Huston, A. C., \& WRIGHT, J. C. (1983). Children's processing of television: The informative functions of formal features. In J. Bryant \& D. R. Anderson (Eds.), Children's understanding of television: Research on attention and comprehension (pp. 35-68). New York: Academic Press.

Huston, A. C., Wright, J. C., Wartella, E., Rice, M. L., WatKINS, B. A., Campbell, T., \& PotTs, R. (1981). Communicating more than content: Formal features of children's television programs. Joumal of Communication, 31, 32-48.

Jenkins, J. J., Wald, J., \& Pittenger, J. B. (1978). Apprehending pictorial events: An instance of psychological cohesion. Minnesota studies in the philosophy of science (Vol. 9, pp. 129-163). Minneapolis: University of Minnesota Press. 
KRACAUER, S. (1960). Theory of film: The redemption of physical reality. New York: Oxford University Press.

Kraft, R. N., \& Jenkins, J. J. (1977). Memory for lateral orientation of slides in picture stories. Memory \& Cognition, 5, 397-403.

KRAFT, R. N., \& Jenkins, J. J. (1979, May). Memory for lateral orientation of pictures of familiar objects and events. Paper presented at the meeting of the Midwestern Psychological Association, Chicago.

Kraft, R. N., Patterson, J. F., \& Mitchell, N. B. (1986). Distance perception in photographic displays of natural settings. Perceptual \& Motor Skills, 62, 179-186.

LeIBRICH, J., \& WhITE, K. G. (1983). Recognition memory for pictorial events. Memory \& Cognition, 11, 121-128.

MANDLER, J. M., \& JoHnson, N. S. (1976). Some of the thousand words a picture is worth. Journal of Experimental Psychology: Human Learning \& Memory, 2, 529-540.

MANdleR, J. M., \& Ritchey, G. H. (1977). Long-term memory for pictures. Journal of Experimental Psychology: Human Learning \& Memory, 3, 386-396.

MASCELLI, J. (1965). The five C's of cinematography. Hollywood: Cine/Graphic Publications.

METZ, C. (1974). Film language: A semiotics of the cinema. New York: Oxford University Press.

Monaco, J. (1981). How to read a film. New York: Oxford University Press.

NeLSON, R. P. (1977). The design of advertising. Dubuque, IA: Wm. C. Brown.

Osgood, C., SucI, G. J., \& Tannenbaum, P. H. (1957). The measurement of meaning. Urbana: University of Illinois Press.

Pittenger, J. B., \& Jenkins, J. J. (1979). Apprehension of pictorial events: The case of a moving observer in a static environment. Bulletin of the Psychonomic Society, 13, 117-120.

POORE, H. R. (1903). Pictorial composition and the critical judgment of pictures. New York: Baker \& Taylor.

Pudovkin, V. I. (1958). Film technique and film acting. London: Vision Press.

SACHS, J. S. (1967). Recognition memory for syntactic and semantic aspects of connected discourse. Perception \& Psychophysics, 2, 437-442.

SALOMON, G. (1974). Internalization of filmic schematic operations in interaction with learners' aptitudes. Journal of Educational Psychology, 66, 499-511.

SALOMON, G. (1979). Interaction of media, cognition, and learning. San Francisco: Jossey-Bass.

SChachter, S., \& Singer, J. (1962). Cognitive, social, and physiological determinants of emotional state. Psychological Review, 69, 379-399.

SHOEMAKER, D. H. (1964). An analysis of the effects of three vertical camera angles and three lighting ratios on the connotative judgments of photographs of three human models (Doctoral dissertation, Indiana University, 1964). Dissertation Abstracts International, 25, 5650.

Soli, S. D., \& BALCH, W. R. (1976). Performance biases and recognition memory for semantic and formal changes in connected discourse Memory \& Cognition, 4, 673-676.

SontaG, S. (1977). On photography. New York: Dell.

SPOTTISWOOdE, R. (1967), A grammar of the film. Berkeley: University of California Press.
Tannenbaum, P. H., \& Fosdick, J. A. (1960). The effect of lighting angle on the judgment of photographed subjects. Audio-Visual Communication Review, 8, 253-262.

TAYLOR, J. (1964). Design and expression in the visual arts. New York: Dover.

WALD, J. (1980). Perceiving everyday activities: A characterization of visual information for "who does what to 'whom" " (Doctoral dissertation, University of Minnesota). Dissertation Abstracts International, 41, 2809B.

\section{APPENDIX}

Questions for the Cued-Recall Task

\section{BOXES}

Were the boxes significantly obstructing the woman's path?

$$
\text { Yes No Maybe }
$$

\section{THE ENCOUNTER}

Was either doll threatened by the other doll? If so, which one was threatened? (Circle one letter.)
a. Yes-The Male Doll was threatened.
b. Yes-The Female Doll was threatened.
c. No-Neither doll was threatened.

\section{THE SMOKER}

Did the man stop smoking?

Yes No I don't know

\section{HITCHHIKER}

Was anyone feeling threatened? If so, who? (Circle one letter.)

a. Yes-The hitchhiker was feeling threatened.

b. Yes-The driver was feeling threatened.

c. No-Neither was threatened.

\section{BASKETBALL}

Who was the better player? (Circle one letter.)

a. The defense man.

b. The ball handler.

c. Neither.

\section{THE DENTED CAR}

What is your best guess about what happened in THE DENTED CAR? (Circle one letter.)

a. The Man hit the Woman's car.

b. The Woman hit the Man's car.

c. Neither the Man nor the Woman hit the car.

(Manuscript received June 27, 1986; revision accepted for publication November $17,1986$. 